Versuch 12. Grosses Kaninchen. Injection von $18 \mathrm{Ccm}$. einer Mischung, welche $3 \mathrm{Grm}$. 30procentige Essigsäure und $27 \mathrm{Grm}$. Wasser enthält, in die linke Jugularvene. Nachdem $12 \mathrm{Ccm}$. langsam injicirt waren, wurde noch keine Dyspnoe bemerkt; als die übrigen $6 \mathrm{Ccm}$. injicirt wurden, trat plötzlich Dyspnoe auf, der Herzschlag worde schwächer, dann trat unter Erstickungshrämpfen und Exophthalmus der Tod ein. $0 \mathrm{bduction}$ : Rechter Vorhof und Ventrikel stark ansgedehnt durch Blut, welches zum grossen Theil geronnen ist.

Versuch 13. $2 \frac{1}{2} \mathrm{Ccm}$. wasserfreier (100 procentiger) Essigsäure werden mit $100 \mathrm{Ccm}$. Wasser gemischt und davon $40 \mathrm{Ccm}$. in die rechte Jugularvene injicirt. Fast keine Dyspnoe, das Thier ist munter. Nach 2 Tagen wird es todt gefunden. Bei der Obduction findet sich Pneumonie der oberen Lappen beider Lungen in Stadium der rothen Hepatisation.

Die Symptome bei der Injection von verdünnten Säuren in das Blut bestehen in einer unmittelbar darauf eintretenden mebr oder weniger bedeutenden Dyspnoe. Ich halte dieselbe für bedingt durch eine vorübergehende paralysirende Wirkung der Säure auf das Herz, die sich auch durch ein Schwächerwerden des Herzschlages kenntlich macht. War die Menge, oder der Procentgehalt der injicirten Flüssigkeit zu hoch, so wird die paralysirende Wirkung anf das Herz tödtlich, und es tritt dann das bekannte Bild dieser Paralyse: sehr bedeutende Dyspnoe, Krämpfe, Exophthalmus auf. Bei der Obdnction findet man den rechten Ventrikel mit Blut überfüllt.

Fast von allen Thieren habe ich kurz nach beendigter Injection das aus einem Stich in das Ohr entnommene Blat mikroskopisch untersucht, aber niemals eine Veränderung an den rothen Blutkörperchen wahroehmen können. Es war dies auch von vornherein nicht zu erwarten, da einige Minuten nach der Injection die Säture bereits mit dem gesammten Körperblut gemischt, also so verdünnt ist, dass sie eine Schrumpfong der Blatkörperchen nicht mehr bewirken kann.

Die vorstehenden Versuche babe ich im pharmakologischen Institute der Universität angestellt. Herrn Prof. Liebreich, der mir die Räumlichkeiten und Apparate desselben bereitwilligst für die Arbeit zur Benutzung gestattet hat, spreche ich hierdurch meinen Dank aus.

\title{
3.
}

\section{Kritisches zu den sog. Adenomen (Küstner) am Nabel der Kinder.}

Von Dr. Kolaczek, erstem Assistenzarzte an der chirurg, Klinik zu Breslau.

Rüstner beschreibt S. 286 u. f, dieses Archivs zwei von ihm sogenannte Adenome des Nabels als bis dahin unbekannte Formen unter den sonst nicht so selten zur Beobachtung gelangenden Granulomen am Nabel von Kindern. Zit- 
nächst gestatte ich mir, hierortș anf zwei ganz ähnliche, 1875 im Arch. f. klin. Chirurgie Bd. 18 von wir unter dem Namen "Entero-Teratome" beschriebene Fälle hinzuweisen, deren Kenntniss Herro $K$ üstner die Deutung und Herleitung seiner beiden, ibm einige Verlegenbeit bereitenden Befunde sicherlich erleichtert bätte. Wenn, wie Kästner selbst hervorhebt, die Drüsengebilde der kleinen Tumoren auf's Haar den Lieberkühn'schen Schläuchen glichen, so erscheint es schwer begreiffich, wie er, da das Gute so nahe lag, sich veranlasst seben konnte, in die Ferne zu schweifen und mit einem histologisch so differenten Gebilde, wie es die Allantoisreste im Nabelstrange sind, auf die Möglichlieit ihrer Schuld an der Wucherung hin so stregg in's Gericht zu gehen. Natürlich musste er von denselben trotz Enţwickelung einer gewissen Gelehrsamkeit vollständig abstrahiren. Die von mir a. o. 0 . in Kärze citirte Literatur hätte für $K$ üstner hingereicht, um die Persistenz des D. omphalo-mesaraicus, als dessen Ausstülpung ich die von mir bescbriebenen Geschwülste aufgefasst babe, leicht erklärlich zu finden. So aber verhalf erst die vor Karzem von Ablfeld wiederholte Entdeclsung eines manchmal beim Neagebornen noch persistirenden, vom Mesenterium bis zum Nabelbläschen reichenden Dotterganges zur ricbtigen Diagnose.

Aber das Missgeschick verfolgt $k u ̈ s t n e r$ noch in einer anderen Bezieuung. Mit welchem Rechte nehmlich, muss man fragen, nennt Küstner diese Miniaturgeschwülste Adenome? Eine Geschwulst, welche, wie Küstner selbst sagt, und die beigegebene Abbildung unzweideutig zeigt, bei Weitem überwiegend aus glatten Muskelfasern bestelt und nur an der Oberfläche eine ziemlich regelmässig pálissadenartig angeordnete Schicht von Cylinderschläuchen ganz vom Ausseben -der Lieberkäbn'schen Drüsen trägt, darf nach meinem Dafürhalten niemals Adenom genannt werden, selbst wenn Kästner eine über hie und da vorkommende gablige Spaltung der Schlauchenden hinausgehende Hyperplasie des Drüsenstratum constatirt hätte. A potiori fit denominatio; $K$ ïstner bäte daher seinen Tumoren eher den Namen "Leiomyom" beilegen können. Vom Intestinaltractus ausgehende Adenome gewähren ein ganz anderes Bild, vor Allem eine regellose Wucherung in die Darmschichten hinein.

Es erscheint fraglich, ob die kleinen Geschwälste überhaupt als Neubildungen aufgefasst werden dürfen, Ich halte es für wahrscheinlicher, dass es einfache Ausstülpungen eines Wandabschnittes, in gewissen Fällen vielleicht eine vollständige Invagination des Dotterganges sind, allenfalls mit einer geringen Hyperplasie aller denselben bildenden Elemente. Nach dem Vorgange Waldeyer's nannte ich früber diese kleinen Tumoren Entera-Teratome, deren Matrix ein im Nabelringe abgeschnürtes Darmdivertikel sein sollte. Meiner Anffassung über die Entstehung derselben würde es aber mehr entsprechen, sie einfach als partielle Prolapse des zofolge einer Bildungshemmung noch bestehenden D. vitello-intestinalis durch den nicht zur Vernarbung kommenden Nabelring anzusehen. Im Uebrigen erlaube ich mir auf meine erste Publication zu verweisen.

Anschliessend benutze ich diese Gelegenheit, um zu erwăhnen, dass ich seitdem im Laufe des Jahres 1876 drei neue Fälle von kleinen Tumoren am Nabel von Kindern in der chirurgischen Klinik zu beobachten Gelegenheit gehabt habe. Davon war nur ein Fall ein solcber woblcharakterisirter Prolaps des Dotterganges, während die beiden anderen einfache erbsengrosse Granulome waren. Jener gebörte einem 10 monatlichen Mädchen an, war bald nach Abfall des Nabelschnurrestes in seinen Anfängen bemerkt worden und wuchs unter Bildung eines Stieles bis zum Umfange einer grossen Erbse.

Uebereinstimmend mit K üstner bemerke ich, dass die Granulome gewöbulich bei ganz jungen Kindern (die beiden anderen Fälle betrafen kaum 6 Wochen alte), die Prolapse dagegen, wohl weil sie sich viel langsamer entwickeln, viel später zur Beobachtung kommen. In den früher von mir beschbriebenen Fällen war das eine Kind $1 \frac{1}{3}$ Jahr, das andere sogar 4 Jahre alt. 